\section{A lerture}

Oะ THE

\section{FTIDENCES OF ALRICULAR FIBRILLATION, TRIAATED HISTORICALLY. \\ Delivered at Cimersity College Hospital,} BY

THOMAS LEWIS, M.D., M.R.C.P., D.Sc.,

IMCTCRER IN CARDIAC PATHOLOGY, UNIVERSTTY COLIEGM HOSPITAL TY OF LONDON HOSPITAL FOR DISEASES OF THE CHEST.

Ir is not always an easy task to choose a subject for an isolated and formal hospital lecture, and it has been especially difficult for me in that my recognized function as a lecturer covers a small field. It occurred to me that, spealking in this building, I could not do better than.select a subject in which University College Hospital may claim a special interest, and describe to you the course auc result of certain observations which have been made in this school since many of you joined it. I refer to an affection of the heart beat which is now spoken of as iuricular fibrillation.

Let me preface a largely personal narrative by saying that, while the knowledge that fibrillation of the auricles is a common event in clinical cases came to me as a result of my own observations, I can take little credit to myself on that account, but, with others, regard the proof as the inevitable outcome of the introduction of new methods. So, with this introduction, I will recite the history of our know. ledge of this affection in the light of $\mathrm{my}$ own experience during the past three years. If this recital does nothing more, it may help to emphasize the limitations of our methods as we cmploy them in investigating disease, and impress the necessity of grasping any new means within our reach of forwarding our object-tho elucidation of himan maladies. You know how .closely disease is scrutinized by hosts of ready workers; and you will discover, if it is not already known to you, how speedily the advantage of cach new stratagem, and each new engine of warfare, which medical ingenuity invents in its struggle with its enemy, disease, is exhausted.

A new line or means of transit is developed, the opportunity is seized on all sides, a stride is taken; some shuffling adds a little to the progress and establishes the move by fortifying the new position; then comes the long wait until once more new cover or new means of reaching it is perceived, and the slow march is continued.

The history of the recognition of fibrillation of the auricles will impress you with the dimness of our eyes and the opacity of the obstacles which cmbarrass ou vision. You will know how blind we have been to things which, once seen, are so apparent.

The investigation starts so far back that none can see its beginning. Suffice it to say that for many years medical workers have written of a gross irregularity of the ventri cular and arterial pulsations, occurring especially in patients in whom cardiac failure is imminent, and in whom cyanosis, venous engorgenent and dropsy are outstanding features. You all know these patients; you have all seen the picture, hung from time to time as it is in the gallerics of disease which our wards constitute : the body raised with pillows, the haggard and anxious countenance the glistening eye, its white oft tinged with yellow ; the flushed cheeks; the full, plum-coloured and open lips : the laboured breathing; the prominent precordial bulging; the confused and wavy impulses which hurry from inter space to interspace; the swollen legs and belly. Here it is but rarely that one seeks in vain the pulse which bear's distinctive qualities. Its rapid action, the utter disorde of rhythm, the hopeless jumbling of strong pulsations with quick runs of almost imperceptible beats, the changing length of intervening pauses, are all characteristics.

It is this pulse which forms our starting point. It has bcen figured and described by many, but its significance has only lately been realized. Named by Hering the pulsus irregularis perpetuus in 1902, on account of its supposed permanence, it has received close study for many years. But little came of this study, and the similar perturbation of the ventricle, to which it evidently owed its origin, was regarded for a long while as an expression of deficient co-ordination in the heart. The complexity of the movements seerned to defy investigation.

The firgt real step came with Mackenzie's observation, that whenever such a pulse is found, no trace of auricular' activity can be identified (Fig. 1). Mackenzie had discovered a means of obtaining graphic records from the jugular pulse, and the curves obtained were really indices of the pressure changes in the right auricle. He developed a ncw method - the analysis of irregularities of the heart-by recording the contractions in its several chambers. In a normal venous curve each upstrolke of the carotid is preceded by a prominent wave (Fig. 1, a) known to result from auricular systole (a). This wave is missing whenever the pulse shows the characteristic irregularity. Moreover, he showed that it vanishes when the irregularity suddenly appears (Fig. 1, B)

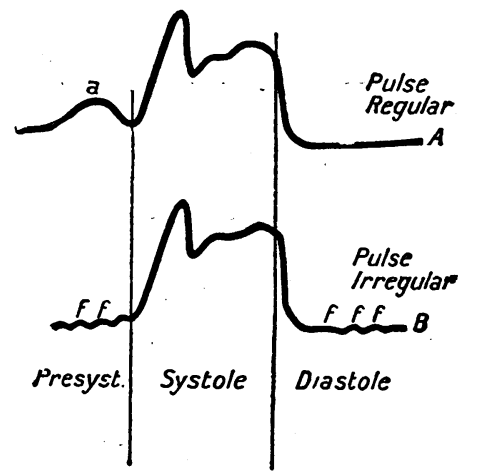

Fis. 1-A diagram of the jugular pulse: $A$, when the heart beats regularly; 13 , when it shows the irregularity described in this lec ture. In $\Lambda$, the pressstolic pulsation ${ }$, which is due to the auricular contraction, is present. In $B$ it has disappeared comin the jugular the pulse is slow but irregular, a may be replacea

in a patient whose pulse has previously been regular. Another fact was elicited by the same worlier. He noticed in a case of mitral stenosis that, where a presystolic murmur had been present, this murmur was lost when the pulse became disorderly. - He rightly attributed the original murmur to auricular systole, and explained the two phenomena, namely, the absence of auricular pulsation in the neck and the absence of auricular murmur in the chest, by supposing a change in the action of the auricle. The actual change postulated was paralysis of the auricle. But Mackenzie, on continuing his researches, found not only that with the restoration of the regular rhythm the auricular wave is restored, but that, in cases which succumb without such restoration, the right auricle may show considerable hypertrophy. These facts ultimately led him to the rejection of his first hypothesis. Believing that a hypertrophied auricle could not remain inactive, and holding abrupt paralysis and abrupt renewal of the auricular systole to be improbable, he sought a new explanation and concluded that auricle and ventricle contract together; for under these circumstances the evidences of the auricular contraction would be buried in the ventricular systole. But simultaneous contraction of auricle and ventricle required explanation; and Mackenzie, influenced by certain histological findings, expressed the view that auricle and ventricle commence their contractions together because the stimulus awakening contraction starts in the tissue which lies between them and unites them, namely, the upper end or "node" of the auriculoventricular bundle. Here is the origin of the term "nodal rhythm."

I have wandered from facts to hypothesis, and now return; the same papers which located the disturbance in the node emphasized the invariable association of the irregular pulse with the absence of signs of auricular activity. The importance of this emphasis was considerable, for it materially helped to establish the irregularity as one sui generis. This should be clear. If we find scattered bacteria which have a fixed and distinctive microscopic appearance, they are not therefore regarded as forming a single and distinct type; but if their growth in culture media is associated with constant phenomena, the culture tests are further evidence that we deal with 
a single organism. So with the irregularity : it presented listinctive qualities wherever found-evidence in itself insufficient though suggestire. But the discovery of a second constant character, the change in auricular mechanism, bore witness to the view that a single and distinct disorder was under observation.

Such was the position when first I became acquainted with it. It was known from Mackenzie's work that a gross irregularity of the heart was always accompanied by a change in auricular action, and, further, the irregularity seemed to be an entity separable from all other cardiac disturbances. Yet at that time the first generalization was alone outstanding, and there was always a feeling of some insecurity in regard to the second. At this time too (1908), the "nodal rhythm" hypothesis was at its acme; in this country, at all events, it was generally regarded with favour, and the term had been widely adopted. It is difficult for me to say, looking back, though it is not so far away, to what extent I regarded it as a probable explanation. My papers, written at that time are guardełly expressed when the tern "nodal rhythm" is used: I was certainly far from a whole-hearted acceptance of it.

The a walkening was a sudden one. In the first week of October, 1909, a man came to my out-patient department at the City of London Hospital ; he showed paroxysms of a peculiar form of tachycardia. It is not necessary to enter into a detailed description of the curves obtained from him at this and his subsequent attendances at University College Hospital. It will be sufficient if it is stated that I was confronted with a case in which I believed that a rhythm coming from the "node" was clearly demonstrable. It was a now method, namely the electro-cardiographic, which gave the facts to argue from. It was this patient who first convinced me that the heart irregularity of which I speak to-day conld not be aue to a "nodal rhythm," for the signs which he presented were totally different from those exhibited by the other patients. His attacks were of regular tachycardia, and it brought home the contrast, and empliasized the irregularity of the other condition as its leading quality. From the day on which I first saw this patient my interest was centred in the cause of the irregularity, so commonly seen in heart failure, the condition then attributed by others to "nodal rhythm."

In the introductory remarks reference was made to blinduess to facts which afterwards seem so evident. At this time, when I felt that the "nodal rhythm" hypothesis was no longer tenable, a series of electrocardiographic curves from dogs in which the auricle was fibrillating (as a result of stimulation with a faradic current), and a second series from patients collected in the wards of this hospital, and in whom the irregularity in question was present, were in my possession; yet for some little while I failed to perceive that the secret lay almost bare before my eyes; and this was the more surprising, for in a paper already written and in the press $\%$ I had briefly described both series of electric curves.

We may now go back to a paper written by Cushny and Edmunds. In 1906 these authors described the arterial curves obtained in dogs when the auricle was thrown into fibrillation, and they compared them with the curves of a patient in whom paroxysms of irregular tachycardia had occurred from time to time. They tentatively suggested that the irregularity might have liad a similar origin in patient and dog. I believe that it was a remembrance of this paper, read some time before and forgotten, which finally led me to examine the irregularity of auricular tibrillation more carefully.

Comparing the electric curves in my possession, it immediately became obvious that discovery was not far away, and a further and larger series of jugular and electric curves were taken from a dog. My conviction on the subject dates from the experiment performed on this animal on November 11th, 1909. Having sufficient data I visited Dr. Mackenzie, for it was imperative that if the new view were to gather force I should win his assent. In taking venous curves from the dog I used the ordinary clinical polygraph, obtaining venous and radial curves, so that they liad the appearance of clinical records.

The paper was actually published in Herrt, 1909, vol. i, issued on November 1st, 1909, and the descriptions appear in footnotes on
ji). 119 and 127.
There were normal curves showing $a$ waves, and curves from the fibrillating heart in which the venous pulse was of the ventricular form, and from which all sign of auriculai contraction had vanished. I placed them before him.without comment, and he stated his belief, as I had hoped, that they were from a patient with "nodal rhythm." From this moment my task was easy, for the electric curves which I had obtained were equally convincing.

It was in this manner that the auricular fibrillation theory won Dr. Mackenzie's support-support so generously given and so valuable, for it was withdrawn from the rival hypothesis, " nodal rhythm.". But several points remained to be cleared. In some of the venous curves from patients in whom the heart-rate was slow, very small oscillations occurred in the venous curves (Fig. 1, B, $f$ ); they had been described by Mackenzie, and he had actually attributed them, in the year of Cushny and Edmunds's paper, to fibrillation of the auricle, but in a later publication he stated that the waves which he had taken for those produced by a fibrillating auricle were in reality the result of a fault in the methor of registration. These little waves now assumed more consequence, and by stimulating the vagus in an animal in which the auricle was fibrillating and thereby slowing the ventricle, I was able to show that such waves are actually produced by a fibrillating auricle.

The position of the evidence at this stage may be sumed up in the statement that the arterial, venous, and electric curves had been found identical in experimental auricular fibrillation on the one hand and in the irregular hearts of patients on the other. It was then that I published my preliminary communication. ${ }^{1}$ Almost immediately afterwards a paper by Rothberger and Winterburg came into my hands for the first time, and in it these writers also emphasized the similarity of the electric curves in the experimental and clinical conditions. The observations of Rothberger and Winterburg actually preceded my own, and were published in July, 1909; they have since been confirmed by a number of other workers.

Now the similarity of the curves taken in three ways from animal and man constituted very striking evidence; yet the proof to-day is based on these and a number of still more convincing observations.

In the remainder of this lecture this evidence will be dealt with, and I will begin with a detailed description of the electro-cardiographic curves. In my introductory remarks I spoke of advance in knowledge when a new method is discovered. It is to Einthoven's string galvanometer that we are indebted for the ultimate solution of the problem-the problem of the causation of the gross irregularity which is seen in clinical subjects. When you connect the limbs of a patient (for example, the right arm and left leg) by means of baths of salt solution and wires to this sensivive instrument, it gives a record of the heart beat, which depends upon the electric current evolved in the heart by the contraction of its muscle.

In an electro-cardiogram from a normal human subject each heart beat is represented by three chief movements of the recording instrument (sce Fig. 2). The first of these (marked $\mathbf{p}$ ) is due to auricular contraction. Inspect the ventricular portion of the curve; $\mathrm{r}$ is a stecp and pointed summit, while $\mathrm{T}$ is broad and rounded. The shape of this whole ventricular curve, as we now know, is signifi. cant of contraction of the ventricle in a given direction. Such curves are yielded when the ventricle contracts in response to an excitation coming to it from the direction of the auricle (that is to say, through the bundle), and by no other form of ventricular contraction.

Now the curves of patients who have complete pulse irregularity give several important pieces of information. I show such a curve in Fig. 3 . You see the peaks, $\mathrm{R}$ and $\mathrm{T}$, which represent ventricular contraction. The individual cycles closely resemble individual normal cycles. The conclusion to be drawn from this fact will be obvious: the ventricle has received its impulse from the direction of the auricle and the disturbance in the mechanism of the heart beat as a whole must thereforc be sought in the ciuricle. Secondly, you note that $\mathrm{P}$, the auricular summit, is not present, a fact which confirms the findings of the venous tracings and emphasizes the absence of a co-ordinate and presystolic auricular contraction. Thirdly, you will be struck by the presence of a number of smail 
oscillations running throughout the whole curve. The electro-cardiograms from these cases show four things :

1. The absence of a normal auricular contraction.

2. The presence of a type of ventricular beat which indicates its origin in an impulse received from the auricle.

3. The special oscillations.

4. Constancy of the picture, from patient to patient, in respect of the first three points.

We may deal with the last first. The constancy in the type of electric curve proved finally that the gross irregularity is a single and isolated condition, a disturbance sui gencris. But what of the oscillations? We have seen that the experimental curves of fibrillation of the auricle had been found to be similar. They present similar oscillations. Further experiment upon the dog quickly revealed the origin of these oscillations in the fibrillating auricle, for the oscillations are maximal when the wires connect this heart chamber directly to the galvanometer. No such oscillations, or only very much smaller ones, and these transmitted, are seen when the instrument is connected either to the ventricle or to other parts of the body. It seemed desirable that similar evidence should be obtained in the human subject, and this more especially as the oscillations in human curves had been ascribed by Hering to tremor
The oscillations come, as I have been able to show recently, from an area of chest wall which gives, when the heart beats normally, the largest electric summit corresponding to auricular systole.

I now come to what I regard as the last and most conclusive proof of the theory. The appearance of a fibrillating auricle is quite distinctive. It does not contract co-ordinately - that is to say, as a whole-but its walls stand in diastole, a position of virtual paralysis; yet inspection of the surface shows that its muscle is broken up into a multitude of small areas, each of which seems to be contracting vigorously, but with no relation to the contraction in surrounding areas. When you compare the appearances of co-ordinately contracting and fibrillating auricle, you may draw parallels between this chamber and a surface of water, disturbed on the one hand by great billows and on the other by a downpour of rain. In the normally beating heart the regular waves of contraction give rise to regular beats of the ventricle; in fibrillation haphazard impulses issue from the auricular turmoil and stimulate the ventricle. Thus the irregularity of the ventricular beating is produced. But that is not the point to be emphasized, though it explains the pulse irregularity, an explanation which no oth $\urcorner$ hypothesis attempts. The point to lay stress upon is that the visible signs in the heart are distinctive and easily recognizable.

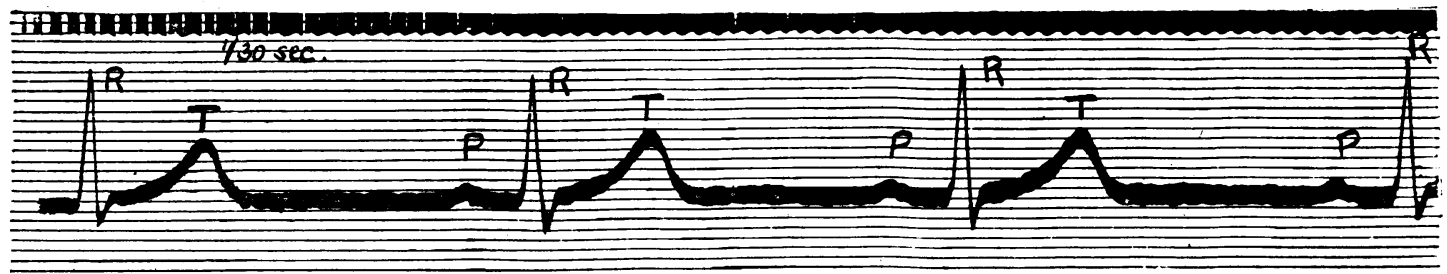

Fig. 2.-An electro-cardi gram from a normal subject, showing the usual electric variations, $P, R$, and $T$; $P$ corresponds to auricular contraction, $\mathrm{R}$ and $\mathrm{T}$ correspond to ventricular systole. The time is in second.

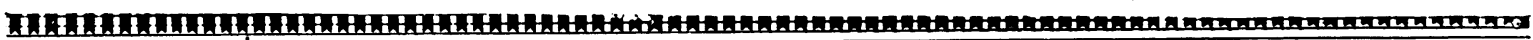

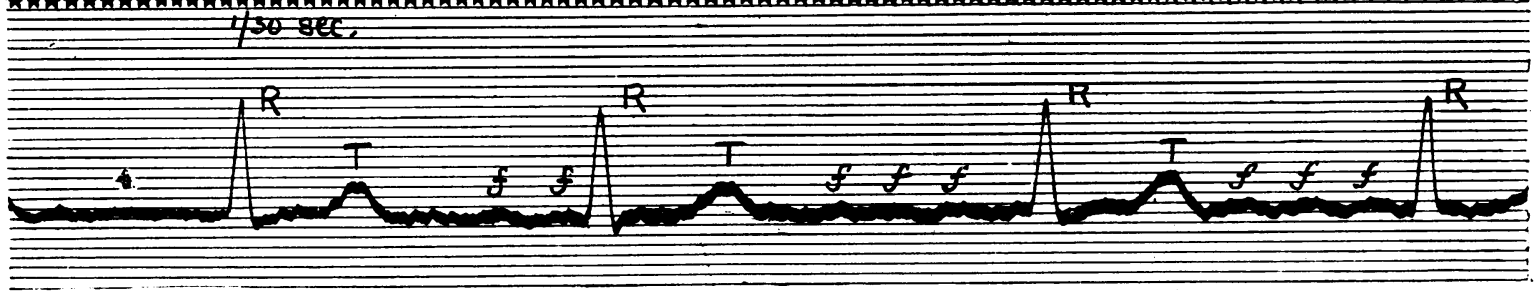

Fig. 3.-An electro-cardiogram from a patient showing complete heart irregularity. The ventricular variations, $\mathrm{R}$ and $\mathrm{T}$, are seen hough they are not placed rest

of the body muscles. The required evidence was obtained by discarding the usual points of contact-namely, right hand and left foot; for if such points are joined to the galvanometer the whole heart and whole trunk and two of the limbs are interposed between the points of contact, and the oscillations in the curve might come from any part of this tissue mass. The galvanometer was connected to the end and base of each separate limb; no oscillations came from either arm or leg. Similarly it was shown that none come from either abdominal or back muscles, but that as soon as the contacts are brought near the heart the oscillations become prominent. Using smaller electrodes as contacts, and strdying the area of the precordium alone, in a case where the right auricle was cnlarged, it was found, further, that the oscillations are largest when the electrodes lie directly over the right or superficial auricle. This auricle or its immediate neighbourhood was fixed as the point of origin of the oscillations, and as the oscillations were found to be continuous throughout the whole cardiac cycle it became evident that such oscillations could be produced only by a muscle mass in continual activity and lying in this region. A fibrillating auricle alone fulfilled these conditions. This-the location of the maximal oscillations and the demonstration that they are continuous-is one of the strongest eridences which we now possess in support of the occurrence of auricular fibrillation in the cases considered.
You will sce from what has been said, how important an actual view of an auricle would be if the heart beat in a grossly irregular fashion. The opportumity came when, in searching for similar disease in the lower animals, I found it in the horse. Largely through the kindness of Dr. Woodruff-whom many of you know, for as a veterinary surgcon he came to study human ailments in this hospital-I was able to show that horses are subject to the same heart disorder, and that the curves given by such hearts are of the same form as those seen in man. The final opportunity of examining a lorse suffering from a degenerate heart and giving the recognized signs occurred on Bulford Plain. The chest was opened while the heart was still beating, and I obtained, as did those with me, a clear view of a fibrillating auricle, brought to this state, not by experimental interference, but by disease. It is this observation which has dissolved remaining doubt and which has placed the theory in so secure a position. Wo now linow quite definitely that auricular fibrillation may occur and persist as a manifestation of disease.

Is ther any further evidence which might be obtained? Yes, in two ways! One has been indicated already. Sooner or later a fibrillating auricle will be seen in the human chest, opened by a surgeon for the relief of his patient. The second is, perhaps, less satisfactory to the cnd we consider. You know that the rabbit's heart may be rerived after death by perfusion and that activity may 
be sustained for considerable periods, but you may not lnow that the same has been sbown for the human heart several hours after death. It is quite within the bounds of possibility that if, in the hands of one accustomed to the method, a heart is taken from one of the patients some while after death, the revival of such a heart may be possible. And it is also probable that in reviving it will return to its former mode of beating-that is to say, the auricle will be seen in fibrillation.

But these are facts which it is for the future to reveal. For the present we must rest content with the proof as I have given it.

Finally, let me refer quite briefly to the results of this conclusion. It explains not oniy the irregularity as we witness it, but it explains almost all the remaining phenomena which are associated with it as a mechanismfacts which I pointed out in my first communication.

When a healthy dog's auricle passes into fibrillation, the ventricle doubles or trebles its original rate; the gross irregularity of our patients is accompanied by tachycardia. The conclusion explains why digitalis acts so magically in slowing such hearts, for digitalis produces heart-block and heart-block slows the ventricle when the auricle fibrillates. It also explains the spontaneous slowing or original slowness of the ventricular action in some patients, for here disease has affected the conducting tissues and has impeded the rapid and irregular impulses from reaching the ventricle.

In brief, the original rapidity of the pulse and its irregularity, the character of the irregularity, the loss of the auricular wave in the neck, the loss of the $P$ summit in the electro-cardiogram, the loss of presystolic murmurs, the presence of rapid oscillations in the venous curve, the presence of oscillations in the electro-cardiogram, the varying rate of the ventricle in a single patient or from patient to patient, the action of digitalis-each and all are clear once the true explanation of the mechanism is grasped. And this explanation, as I have shown you, is that in such cases we have to deal with fibrillating auricles.

REFERENCE.

1 British Medical Journal, November 27th, 1909.

\section{THE EFFECTS UPON THE HEART OF SOLUBLE DIGITOXIN, AN ISOLATED GLUCOSIDE OF THE DIGITALIS GROUP.}

BY

BENJAMIN MOORE, M.A., D.Sc., M.R.C.S., L.R.C.P., PROFESSOR OF BIO-CHEMISTRY, CNIVERSITY OF LIVERPOOL.

(From the Bio-chemical Laboratory, University of Liverpool.)

A LTHOUgh digitalis is one of the most valuable of all our cardiac drugs,-its therapeutic administration still lies at a stage of development comparable to that of the use of decoctions of cinchona bark before the isolation of quinine.

The physician is still, unfortunately, forced to prescribe an infusion or tincture of digitalis leaves prepared on the same principles as a cup of tea, although the toxicity of the product so administered may vary as much as that of the domestic beverage.

As a matter of fact, when either an infusion or tincture of digitalis leaves is prescribed, not one remedial agent is employed but a blunderbuss of about half a dozen bodies with powerful cardiac action, some undoubtedly favourable for the condition to be combated, others as equally certainly unfavourable in their continued effects npon cardiac muscle.

The reason for this state of affairs in regard to digitalis therapy does not lie so much in a want of knowledge as in a plethora of knowledge, for instead of having in the digitalis leaves one predominatingly important active substance, as in the case of quinine or caffeine, we have as in the case of the morphine alkaloids, a number of active bodies requiring a great deal of experimental labour and clinical experience to decide between their relative values and uses.

In order to surmount some of these difficulties in the clinical use of digitalis there has been introduced in recent years the process of physiological standardization in order to give some idea of the approximate strength, as a kind of therapeutic battery, of the complex group of bodies probably present in varying relative amount in any given galenical preparation, such as pharmacopoeial infusion or tincture.

Two methods which have been employed for this standardization are (1) the determination of the minimal amount which will, when injected into a lymph sac, cause complete stoppage of the heart of a frog of average size (20 grams weight) within one hour, and (2) the determination of the minimal concentration in Ringer's solution, which when perfused through the isolated mammalian heart, stops all action of tl e ventricle within one hour. The amount of a good tincture of digitalis required in the first method should not excecd 0.3 to 0.4 c.cm.; and, in the second method, the digitalis preparation should stop the heart within the hour at a clilution of 1 in 200 . A third method of experimentation more recently employed by Waller, with interesting results, is to study the effects of the drug in arresting the contractile power of skeletal muscle immersed in the diluted drug. This method has the merit of greater simplicity, and the results seem to resemble closely those obtained with cardiac muscle itsclf

But although those methods of physiological stanclardization may be safely relied on for giving information as to the genuine digitalis nature of a commercial sample, and also some indication as to the careful preparation from "good" leaves, still, as satisfactory scientific and practical methods of dosage they fail in two important aspects.

In the first place, there is no definite standard such as an isolated glucoside of this class would give, if obtainable and universally agreed upon as a standard; there are many isolated products all differing from one another, some soluble and others insoluble, and all varying in their action upon the heart, and as yet pharmacologists have not been able to select any one of these as a unit.

Secondly, the proposed standardization test is a test of "killing power," and physicians do not want to kill, but curc. Underlying this test of killing within a certain time by ventricular arrest is the tacit assumption that it is the same body which kills and produces the favourable therapeutic effect. On any other hypothesis the so-called physiological standardization is meaningless.

The basis of the whole process is that digitalis in small doses stimulates cardiac muscle, and in large doses paralyses it, and hence if in the case of a given preparation we determine the larger dose which kills, we can logically infer what is the smaller dose which will just develop the beneficial therapeutic effect. Now, however sound such argumentation might be in the case of a single active body difficult to isolate, and hence standardized by such an indirect method, it loses all application when dealing with at least four bodies so very different in action and toxicity as are the glucosides of digitalis leaves. The test would only hold if there were the same ratio between maximum therapeutic action and minimal lethal dose for each of these bodies, and experience of both pharmacologist and clinician demonstrates that this does not hold true.

This line of thought holds good not only for the standardization of digitalis, but also for the decision as to whether the usual unknown mixture of the Pharmacopoeia should be still used, or whether the active glucosides should be isolated and used separately. There is no question that at least one of the glucosides present in the digitalis leaf-namely, digitonin-is injurious in its action, and onght to be eliminated if possible; and amongst the remaining members of the group there can be little doubt that these vary amongst each other in relative toxicity and degree of excitatory action.

It would have been more scientific to scparate these artire bodies and make use of them according to the clinical indications in varying cases rather than to fire off a blunderbuss of them all in unknown proportions at the patient's heart.

Here it should be emphasized that it is not maximum toxicity or brute strength that is to be aimed at. If it were so, strophanthin, which is much more powerful, would in all cases be prescribed; but it is easy enough to stop a heart with any of these drugs given in sufficient dose. The active agent to pick out is that one which possesses what might be described as the greatest factor of safety, that is, the highest ratio between the minimal lethal dose and the dose giving a good therapeutic effect. Some attention ought also to be paid to the possibility of accurate 